\section{Crapemyrtle Genotype $\times$ Environment Interactions, and Trait Stability for Plant Height, Leaf-out, and Flowering}

\author{
Cecil T. Pounders ${ }^{1,5}$
}

USDA-ARS, Thad Cochran Southern Horticultural Laboratory, 810 Highway 26 West, P.O. Box 287, Poplarville, MS 39470

Eugene K. Blythe ${ }^{2}$ Mississippi State University, Coastal Research and Extension Center, South Mississippi Branch Experiment Station, Poplarville, MS 39470

Donna C. Fare ${ }^{3}$

USDA-ARS, U.S. National Arboretum, Otis L. Floyd Nursery Research Center, McMinnville, TN 37110

Gary W. Knox ${ }^{4}$

Department of Environmental Horticulture, University of Florida, North Florida Research and Education Center, Quincy, FL 32351

Jeff L. Sibley ${ }^{4}$

Department of Horticulture, Auburn University, Auburn, AL 36849

Additional index words. Lagerstroemia indica, L. fauriei, L. indica $\times$ L. fauriei, best linear unbiased prediction (BLUP), cluster analysis, stability analysis, cultivar evaluations

\begin{abstract}
This study reports on the performance of 34 clones of crapemyrtle (Lagerstroemia indica L., L. fauriei Koehne, and L. indica $\times$ L. fauriei hybrids) grown in field plots at four locations representative of different environments in the southeastern United States. Traits evaluated were spring leaf-out and initiation of flowering in the second season after field planting and plant height after 3 years of growth. Cluster analysis (Ward's method) was used for grouping and comparison of means across locations for each trait. Best linear unbiased prediction was used for estimating random effects in linear and generalized linear mixed models to better determine the general performance of the clones under a variety of environmental conditions. Each clone's trait stability was quantified using the regression of an individual genotype's performance for each of the three studied traits on an environmental index based on the trait mean for all genotypes grown in an environment. Sequence of clone leaf-out and size rankings were more stable across the environments than the sequence in which the various clones initiated flowering. L. fauriei clones and clones originating from the initial cross between $L$. indica and $L$. fauriei were generally later to leaf out, earlier to flower, and more vigorous growers than $L$. indica or the complex $L$. indica $\times L$. fauriei clones that were evaluated. First flowering was affected by environmental variation more with interspecific hybrids than with $L$. fauriei and $L$. indica clones. Performance, particularly with respect to plant height, of several clones did not agree with previously published classifications. Information generated by this study will allow crapemyrtle breeders, landscape professionals, and consumers to better select the most appropriate crapemyrtle clone for a particular application.
\end{abstract}

\footnotetext{
Received for publication 16 Oct. 2009. Accepted for publication 23 Nov. 2009.

Mention of a trademark, proprietary product, or vendor does not constitute a guarantee or warranty of the product by the U.S. Department of Agriculture or other institutions and does not imply its approval to the exclusion of other products or vendors that may also be suitable.

${ }^{1}$ Research Geneticist.

${ }^{2}$ Assistant Research Professor.

${ }^{3}$ Research Horticulturist.

${ }^{4}$ Professor.

${ }^{5}$ To whom reprint requests should be addressed; e-mail cecil.pounders@ars.usda.gov.
}

have been selected over the past century (Dix, 1999). Heirloom cultivars were selected as chance seedlings based on unique flower color or growth habit (Egolf and Andrick, 1978). Otto Spring of Okmulgee, OK, and Donald Egolf at the U.S. National Arboretum (USNA) pioneered controlled breeding of crapemyrtles in the United States and many cultivars released during the past 40 years originated from their efforts. Research at the USNA indicated that L. fauriei was coldhardy and resistant to powdery mildew, coupled with the discovery of a chance interspecific hybrid between this species and $L$. indica in Texas (Egolf and Andrick, 1978), led to the introgression of L. fauriei into the USNA breeding program as a source of powdery mildew resistance. After selection of powdery mildew-resistant interspecific progeny, breeding focused on half-sib and backcrosses to introduce resistance into predominantly $L$. indica germplasm. More than 20 cultivars with high levels of powdery mildew resistance (Egolf, 1967, 1981a, 1981b, 1986a, 1986b, 1987a, 1987b, 1990; Pooler, 2006; Pooler and Dix, 1999) have been released by the USNA. Several popular cultivars with unique flower colors were derived by continued breeding with Otto Spring's germplasm (Whitcomb, 1985, 1999, 2000a, 2000b, 2004; Whitcomb et al., 1984).

Crapemyrtle cultivars have been evaluated for a number of traits, including growth (Bolques and Knox, 1997; Cabrera and Devereaux, 1999; Creech et al., 1999; Knox, 1996; Knox and Norcini, 1991; Laiche and Anderson, 1996), cold tolerance (Davis and Fare, 1995; Hayes and Lindstrom, 1992; Lindstrom et al., 2002), nutrient use (Cabrera, 2003; Cabrera and Devereaux, 1998; Devereaux, 1996; Martin and Ruter, 1996), flowering (Bolques and Knox, 1997; Fare, 1984; Goi and Tanaka, 1976; Guidry, 1977; Pair and Parsons, 1996; Stimart, 1986), resistance to disease (Hagan et al., 1998; Holcomb, 1994; Knox et al., 1993), and insect feeding preferences (Cabrera et al., 2008; Mizell and Knox, 1993; Pettis et al., 2004). Most of these evaluations were based on data from one site over multiple years.

Size categories based on plant height at maturity were first proposed by Egolf and Andrick (1978). Johnson and Dix (1993) pointed out that "at maturity" is a vague term that can lead to misclassification without designation of the age of specimens when the size would be realized. Under the improved system, cultivars are divided into four size categories: dwarf cultivars (less than $1.5 \mathrm{~m}$ at 5 years), semidwarf (1.5 to $3 \mathrm{~m})$, intermediate (3 to $6 \mathrm{~m}$ ), and tree forms (greater than $6 \mathrm{~m}$ ) based on expected height after 10 years for the larger three classes. The revised classification system has been widely used in extension publications and other references comparing crapemyrtle landscape traits (Byers, 1997, 2000; Franklin et al., 2006; Gill and Owens, 2007; Knox, 2008; Wade and Williams-Woodward, 2001; Williams et al., 2000). Classification into the various size categories appears to be based on height data 
reported in the published cultivar releases (Egolf 1967, 1981a, 1981b, 1986a, 1986b, 1987a, 1987b, 1990; Pooler, 2006; Pooler and Dix, 1999; Whitcomb, 1985, 1999, 2000a, 2000b, 2004; Whitcomb et al., 1984) and extrapolation for other cultivars rather than replicated side-by-side comparisons of cultivars at multiple sites. This implies that popular cultivars can be expected to perform in a similar manner in all areas of the United States where crapemyrtle is adapted. None of the growth studies were replicated at multiple locations to determine how sensitive observed traits were to different environments.

Plant phenotypes vary according to the environments where they are evaluated (Hill, 1975). Evaluation of plant traits in diverse environments produces an understanding of genotype $\times$ environment $(\mathrm{G} \times \mathrm{E})$ interactions that affect performance of a particular clone. Such information is important to horticulturists and plant breeders for proper selection of the most appropriate crapemyrtle clone for a particular application. Generally, genotypes with consistent performance in many environments are preferred over those that excel in restricted environments.

Observation of crapemyrtle clones in multiple random environments within the normal range of hardiness would give a much better understanding of the ultimate landscape performance of a clone. This study reports the variation for three traits (week of leaf-out, week of first flowering, plant height) in 34 common crapemyrtle clones (genotypes) observed in four diverse environments within the southeastern United States. Additionally, variation and phenotypic stability were identified for the three traits among the clones.

\section{Materials and Methods}

Thirty-four commonly produced crapemyrtle clones (Table 1) were selected from available clones representing a range of traits from each of the semidwarf (1.5 to $3 \mathrm{~m})$, medium ( 3 to $6 \mathrm{~m}$ ) and tall (greater than $6 \mathrm{~m}$ ) groupings for expected mature size (Franklin et al., 2006). Cuttings from the same ortet of a clone were rooted in the summer of 2002 in 36-cell trays at Poplarville, MS, in ground pine bark supplemented with Osmocote 18N-2.6P-10K (18-6-12) (6-8 month; The Scotts Co., Marysville, $\mathrm{OH}$ ) incorporated at a rate of $5.3 \mathrm{~kg} \cdot \mathrm{m}^{-3}$. Rooted cuttings of the selected clones were distributed to cooperators at four locations (Table 2) in Jan. 2003. Cooperators grew the clones for one growing season in 11.3-L (\#3) nursery containers and then transplanted into field plots in Spring 2004. Immediately after planting, plants at all locations were pruned to a height of $10 \mathrm{~cm}$ before spring budbreak. Cooperators were instructed to follow accepted production practices (fertilization, pest control, supplemental watering) for crapemyrtle production in their area. Growing practices and climatic conditions at the four locations (Table 2) constituted four random growing environments within the southeastern United States.

The field layout at each of the four locations was a randomized complete block design with six blocks containing a single plant of each clone (a total of 204 plants with six replicates per clone at each location).

Data were collected for week of leaf-out (LO) and initiation of flowering (FR) during the 2005 growing season. Plant height (HT) was measured after the 2006 growing season (3 years in the field) when plants were dormant. Weekly readings on LO started at each location beginning when the first plant of any clone displayed fully expanded leaves (Week 1) until the last plant of any clone displayed fully expanded leaves (Week 5 being the latest). Consequently, the week of LO for each plant at a location was designated by a single value from 1 to 5 . During 2005, there were no killing frosts at any location to disrupt the normal sequence of LO for the 34 clones. FR was rated weekly beginning when any plant at a location began flowering (Week 1) until the last plant at the location began flowering (Week 8 being the latest). Therefore, each plant at a location was designated by a single FR value from 1 to 8 .

Preliminary analysis of data was conducted using location, clone, and location $\times$ clone as fixed factors and block(location) as a random factor to confirm our expectations of overall differences in response variables

Table 1. Flower color, parentage, and selector (name and location) of 34 Lagerstroemia clones.

\begin{tabular}{|c|c|c|c|c|c|}
\hline Clone & Code & Flower color & Species parentage & Selector $^{z}$ & $\begin{array}{l}\text { Selector's } \\
\text { location }^{z}\end{array}$ \\
\hline Acoma & $\mathrm{ACO}$ & White & L. indica/L. fauriei & Egolf & $\mathrm{DC}$ \\
\hline Apalachee & APA & Lavender & L. indica/L. fauriei & Egolf & $\mathrm{DC}$ \\
\hline Arapaho & ARA & Red & L. indica/L. fauriei/L. limii & Pooler & $\mathrm{DC}$ \\
\hline Carolina Beauty & $\mathrm{CAB}$ & Red pink & L. indica & Dailey & $\mathrm{SC}$ \\
\hline Catawba & CAT & Purple & L. indica & Egolf & DC \\
\hline Centennial Spirit & CES & Red & L. indica & Whitcomb & $\mathrm{OK}$ \\
\hline Cheyenne & $\mathrm{CHE}$ & Red purple & L. indica/L. fauriei/L. limii & Pooler & $\mathrm{DC}$ \\
\hline Choctaw & $\mathrm{CHO}$ & Pink & L. indica/L. fauriei & Egolf & $\mathrm{DC}$ \\
\hline Christiana & CHR & Red pink & L. indica & Egolf & $\mathrm{DC}$ \\
\hline Country Red & $\mathrm{COU}$ & Red pink & L. indica & Durant & $\mathrm{OK}$ \\
\hline Fantasy & FAN & White & L. fauriei & Raulston & $\mathrm{NC}$ \\
\hline Kiowa & $\mathrm{KIO}$ & White & L. fauriei & Pooler & $\mathrm{DC}$ \\
\hline Miami & MIA & Pink & L. indica/L. fauriei & Egolf & DC \\
\hline Muskogee & MUS & Lavender & L. indica/L. fauriei & Egolf & $\mathrm{DC}$ \\
\hline Natchez & NAT & White & L. indica/L. fauriei & Egolf & DC \\
\hline Osage & OSA & Pink & L. indica/L. fauriei & Egolf & $\mathrm{DC}$ \\
\hline Pecos & PEC & Pink & L. indica/L. fauriei & Egolf & DC \\
\hline Powhatan & POW & Purple & L. indica & Egolf & $\mathrm{DC}$ \\
\hline Sarahs Favorite & SAR & White & L. indica/L. fauriei & Egolf & $\mathrm{DC}$ \\
\hline Sioux & $\mathrm{SIO}$ & Pink & L. indica/L. fauriei & Egolf & $\mathrm{DC}$ \\
\hline Splash of Pink & SPP & Pink/white & L. indica & Bond & TX \\
\hline Tonto & TON & Red pink & L. indica/L. fauriei & Egolf & $\mathrm{DC}$ \\
\hline Townhouse & TOW & White & L. fauriei & Raulston & $\mathrm{NC}$ \\
\hline Tuscarora & TUS & Pink & L. indica/L. fauriei & Egolf & $\mathrm{DC}$ \\
\hline Tuskegee & TKE & Pink & L. indica/L. fauriei & Egolf & $\mathrm{DC}$ \\
\hline Twilight & TWI & Purple & L. indica & Fitzpatrick & TX \\
\hline Velmas Royal Delight & VRD & Purple & L. indica & McDaniel & KS \\
\hline Whit I & RAS & Pink/white & L. indica & Whitcomb & $\mathrm{OK}$ \\
\hline Whit II & DYN & Red & L. indica & Whitcomb & $\mathrm{OK}$ \\
\hline Whit IV & RER & Red & L. indica & Whitcomb & $\mathrm{OK}$ \\
\hline Whit VI & BUC & Blush pink & L. indica & Whitcomb & $\mathrm{OK}$ \\
\hline Whit VII & SIR & Red & L. indica & Whitcomb & $\mathrm{OK}$ \\
\hline Wm. Toovey & WMT & Red pink & L. indica & Howell & $\mathrm{TN}$ \\
\hline Woodlanders Chocolate Soldier & WCS & White & L. fauriei & Mitchell & $\mathrm{SC}$ \\
\hline
\end{tabular}

zelector (name and location) as reported by Dix (1999). 


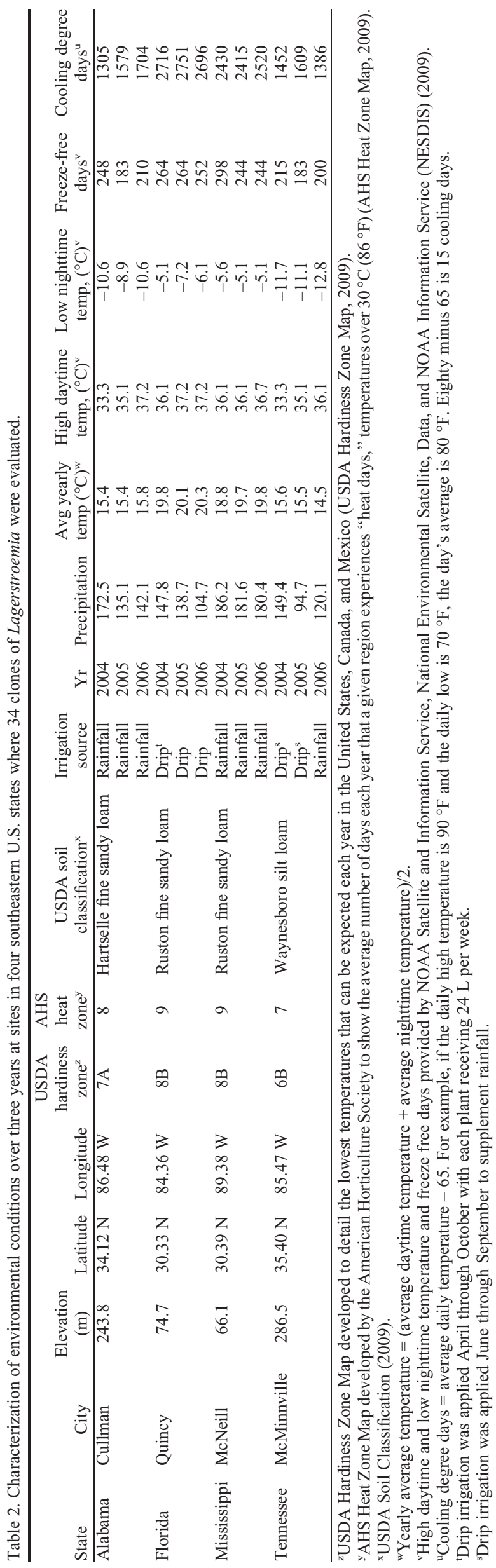

(week of LO, week of first flower, and plant HT traits) among locations and to provide least squares means of the three response variables for each location (across all clones) for later use in analyzing stability of traits for the clones across locations. Subsequent analysis of response data was conducted using clone as a fixed factor and location, location $\times$ clone, and block(location) as random factors.

Plant height data were analyzed using a linear mixed model with the MIXED procedure of SAS (Version 9.2; SAS Institute, Inc., Cary, NC). Week of LO data and week to first flowering data were analyzed using a generalized linear mixed model with a Poisson distribution and a log link function with the GLIMMIX procedure of SAS. Least squares means of the response variables were determined for each clone across all locations for later use in cluster analysis and for correlation analysis. Pearson correlation coefficients between pairs of the response variables were obtained using the CORR procedure of SAS.

Best linear unbiased predictions (BLUPs) for the three response variables provided estimated values of the response variables for each clone at each location taking into account both the fixed and random effects through estimable linear functions (Robinson, 1991). Rather than using the four locations as the entire population and calculating means as simple averages, the locations were considered to be a random sample from a normally distributed population with the BLUPs providing regression toward the overall mean (shrinkage estimation) based on the variance components of the model effects (Littell et al., 2006).

Cluster analysis was used to investigate potential groupings of clones for similarity of week of LO, week of first flowering, and plant height using the least squares means calculated for each clone across all locations. Cluster analysis was conducted using Ward's method with the CLUSTER and TREE procedures of SAS, the number of clusters being determined using $R^{2}$, semipartial $R^{2}$, and between-cluster sum of squares statistics (Blythe and Merhaut, 2007). Descriptive statistics for each cluster for each of the three variables were obtained using the MEANS procedure of SAS.

Stability of traits for the 34 clones across locations was quantitatively assessed for each clone by simple linear regression of each response variable against the means of the respective variable from each location (environmental index), a method that has been useful for evaluating performance and adaptation of agronomic and horticultural crops in different locations and environments (Eberhart and Russell, 1966; Finlay and Wilkinson, 1963; Ortiz and Izquierdo, 1994). Linearity of the regression was checked using both the original data values and the natural logarithm of the data values (Finlay and Wilkinson, 1963). Linearity was improved using the logarithm for week of LO and plant height, but not for week of flowering. 
A clone was considered to be stable if $b_{1}$ (coefficient of regression) was not significantly different from $1, \mathrm{~s}_{\mathrm{d}}{ }^{2}$ (deviation from linearity) $=0$, and $r^{2}$ (coefficient of deter-

mination) greater than 0.50 following the criteria of Ortiz and Izquierdo (1994). The stability characteristic $b_{1}$ was considered consistent if its $\operatorname{SE}\left(\mathrm{s}_{\mathrm{b}}\right)$ was not significantly

Table 3. Tests of fixed effects in linear mixed models evaluating plant height, time to leaf-out ${ }^{z}$ and time to first flower ${ }^{y}$ of 34 clones of Lagerstroemia grown at four locations in the southeastern United States (Quincy, FL; McNeill, MS; Cullman, AL; and McMinnville, TN).

\begin{tabular}{|c|c|c|c|c|}
\hline Fixed effect & Numerator df & Denominator df & F value & Probability $>\mathrm{F}^{\mathrm{x}}$ \\
\hline \multicolumn{5}{|c|}{ Week of leaf-out (location as a fixed effect) } \\
\hline Location & 3 & 20 & 16.82 & $<0.001$ \\
\hline Clone & 33 & 646 & 3.91 & $<0.001$ \\
\hline Location $\times$ clone & 99 & 646 & 0.41 & 1.000 \\
\hline \multicolumn{5}{|c|}{ Week of leaf-out (location as a random effect) } \\
\hline Clone & 33 & 646 & 3.81 & $<0.001$ \\
\hline \multicolumn{5}{|c|}{ Week of first flower (location as a fixed effect) } \\
\hline Location & 3 & 20 & 27.94 & $<0.001$ \\
\hline Clone & 33 & 646 & 8.09 & $<0.001$ \\
\hline Location $\times$ clone & 99 & 646 & 1.76 & $<0.001$ \\
\hline \multicolumn{5}{|c|}{ Week of first flower (location as a random effect) } \\
\hline Clone & 33 & 646 & 5.98 & $<0.001$ \\
\hline \multicolumn{5}{|c|}{ Plant height (location as a fixed effect) } \\
\hline Location & 3 & 20 & 137.69 & $<0.001$ \\
\hline Clone & 33 & 647 & 66.46 & $<0.001$ \\
\hline Location $\times$ clone & 99 & 647 & 4.51 & $<0.001$ \\
\hline \multicolumn{5}{|c|}{ Plant height (location as a random effect) } \\
\hline Clone & 33 & 647 & 66.46 & $<0.001$ \\
\hline
\end{tabular}

different from zero as indicated by deviation of the regression from linearity $\left(\mathrm{s}_{\mathrm{d}}{ }^{2}\right)$.

Stability analysis in this study follows the concept of dynamic stability under which a stable genotype exhibits a varying, but predictable, response to different environments as opposed to the static concept of stability, under which a stable genotype responds at a constant level in different environments (Becker and Leon, 1988). Clones with values of $b_{1} \approx 1$ are considered stable with the response of the clone in different environments being similar to the environmental index (described previously). Values of $b_{1}$ greater than 1 indicate clones that are more sensitive to environment, whereas values of $b_{1}$ less than 1 (and approaching zero) are less sensitive to environment among all clones being evaluated.

To complete the analysis, the stability characteristic $b_{1}$ was plotted against the least squares mean for each clone (across all locations) to assess both characteristics for all clones simultaneously with one plot for each of the three response variables. Horizontal lines were added to the plots to indicate values of $b_{1}$ on the $y$ axis that were statistically different from 1 at the 0.05 significance level, whereas vertical lines were added to the plots for mean values on the $\mathrm{x}$ axis statistically different from the grand mean at the 0.05 significance level, similar

Table 4. Least squares means and best linear unbiased predictions (BLUPs) with 95\% confidence intervals for week of leaf-out of 34 clones of Lagerstroemia grown at four locations in the southeastern United States. ${ }^{z}$

\begin{tabular}{|c|c|c|c|c|c|}
\hline$\overline{\text { Clone }}$ & All locations ${ }^{2}$ & Quincy, FL & McNeill, MS & Cullman, AL & McMinnville, TN \\
\hline ARA & $1.77(1.24-2.53)$ & $1.39(1.02-1.89)$ & $2.00(1.47-2.72)$ & $1.97(1.45-2.68)$ & $1.81(1.33-2.46)$ \\
\hline CAB & $1.86(1.31-2.63)$ & $1.45(1.07-1.97)$ & $2.10(1.55-2.83)$ & $2.06(1.52-2.78)$ & $1.89(1.40-2.56)$ \\
\hline CES & $2.58(1.86-3.57)$ & $2.01(1.53-2.65)$ & $2.91(2.23-3.81)$ & $2.86(2.18-3.74)$ & $2.63(2.00-3.45)$ \\
\hline $\mathrm{CHE}$ & $1.81(1.28-2.58)$ & $1.42(1.04-1.93)$ & $2.05(1.51-2.78)$ & $2.01(1.49-2.73)$ & $1.85(1.36-2.51)$ \\
\hline $\mathrm{CHO}$ & $2.27(1.63-3.15)$ & $1.77(1.34-2.34)$ & $2.56(1.95-3.37)$ & $2.52(1.91-3.31)$ & $2.31(1.76-3.04)$ \\
\hline FAN & $3.84(2.86-5.16)$ & $3.00(2.39-3.78)$ & $4.34(3.48-5.43)$ & $4.26(3.41-5.34)$ & $3.92(3.13-4.91)$ \\
\hline $\mathrm{KIO}$ & $3.78(2.80-5.10)$ & $2.95(2.32-3.76)$ & $4.27(3.39-5.38)$ & $4.19(3.33-5.29)$ & $3.85(3.04-4.88)$ \\
\hline MIA & $2.52(1.83-3.46)$ & $1.97(1.51-2.57)$ & $2.84(2.19-3.69)$ & $2.79(2.15-3.62)$ & $2.57(1.97-3.33)$ \\
\hline MUS & $2.64(1.93-3.62)$ & $2.06(1.59-2.68)$ & $2.98(2.31-3.85)$ & $2.93(2.27-3.78)$ & $2.69(2.08-3.48)$ \\
\hline NAT & $2.72(1.99-3.72)$ & $2.13(1.65-2.75)$ & $3.08(2.39-3.95)$ & $3.02(2.35-3.88)$ & $2.78(2.16-3.57)$ \\
\hline OSA & $3.01(2.21-4.10)$ & $2.36(1.84-3.02)$ & $3.41(2.67-4.35)$ & $3.34(2.62-4.27)$ & $3.07(2.40-3.93)$ \\
\hline PEC & $2.14(1.54-2.99)$ & $1.68(1.26-2.23)$ & $2.42(1.83-3.21)$ & $2.38(1.80-3.15)$ & $2.19(1.65-2.90)$ \\
\hline TOW & $3.88(2.90-5.17)$ & $3.03(2.43-3.78)$ & $4.38(3.54-5.42)$ & $4.30(3.47-5.33)$ & $3.95(3.19-4.90)$ \\
\hline TUS & $2.23(1.60-3.10)$ & $1.74(1.31-2.31)$ & $2.52(1.91-3.32)$ & $2.47(1.88-3.26)$ & $2.27(1.72-3.00)$ \\
\hline TKE & $2.23(1.60-3.10)$ & $1.74(1.31-2.31)$ & $2.52(1.91-3.32)$ & $2.47(1.88-3.26)$ & $2.27(1.72-3.00)$ \\
\hline TWI & $3.46(2.58-4.65)$ & $2.71(2.15-3.41)$ & $3.91(3.13-4.90)$ & $3.84(3.07-4.81)$ & $3.53(2.82-4.43)$ \\
\hline VRD & $3.18(2.35-4.29)$ & $2.48(1.95-3.16)$ & $3.59(2.84-4.53)$ & $3.52(2.79-4.45)$ & $3.24(2.56-4.10)$ \\
\hline RAS & $2.93(2.15-3.98)$ & $2.29(1.79-2.94)$ & $3.31(2.60-4.22)$ & $3.25(2.55-4.14)$ & $2.99(2.34-3.81)$ \\
\hline DYN & $2.35(1.70-3.25)$ & $1.84(1.40-2.42)$ & $2.66(2.03-3.48)$ & $2.61(1.99-3.41)$ & $2.40(1.83-3.14)$ \\
\hline RER & $2.43(1.76-3.36)$ & $1.90(1.45-2.49)$ & $2.75(2.11-3.58)$ & $2.70(2.07-3.52)$ & $2.48(1.90-3.24)$ \\
\hline BUC & $2.82(2.05-3.87)$ & $2.20(1.69-2.87)$ & $3.18(2.47-4.11)$ & $3.13(2.42-4.05)$ & $2.87(2.22-3.72)$ \\
\hline SIR & $2.42(1.75-3.36)$ & $1.89(1.44-2.49)$ & $2.74(2.09-3.59)$ & $2.69(2.05-3.53)$ & $2.47(1.88-3.24)$ \\
\hline WMT & $2.89(2.12-3.93)$ & $2.26(1.76-2.90)$ & $3.26(2.56-4.17)$ & $3.20(2.51-4.09)$ & $2.94(2.30-3.76)$ \\
\hline WCS & $4.37(3.30-5.80)$ & $3.42(2.77-4.21)$ & $4.94(4.04-6.05)$ & $4.85(3.96-5.94)$ & $4.46(3.63-5.47)$ \\
\hline All clones & & $2.06 \mathrm{C}^{\mathrm{y}}$ & $3.07 \mathrm{~A}$ & $3.01 \mathrm{~A}$ & $2.73 \mathrm{~B}$ \\
\hline
\end{tabular}

${ }^{\mathrm{z}}$ Least squares means were calculated for each clone across all locations and BLUPs were calculated for each clone at each location (with location as a random effect). Least squares means were calculated for each location across all clones (with location as a fixed effect in preliminary analysis).

${ }^{y}$ Means at each location for all clones combined followed by the same letter are not significantly different according to the simulation-stepdown method at $\alpha=0.05$. 
to the method of Ortiz and Izquierdo (1994). These features were added to the plots to facilitate general identification of clones that were relatively stable (values of $b_{1}$ close to 1), sensitive, or insensitive to environment and clones that were similar, higher, or lower in mean response compared with the overall mean; they were not intended for development of strict statistical inferences.

\section{Results and Discussion}

Crapemyrtle clones at the four locations were exposed to a wide range of climatic variation typical of the southeastern United States (Table 2). The Alabama and Tennessee locations had shorter growing seasons, colder winter minimum temperatures, and cooler summers than the Florida and Mississippi locations. During the three growing seasons, the Alabama, Florida, and Tennessee locations experienced severe summer droughts, whereas the Mississippi location was in the path of Hurricane Katrina in Aug. 2005.

Correlations between LO and FR, HT and FR, and HT and LO were statistically significant $(P<0.01)$, but weak. The strongest as- sociation was between HT and FR ( $r=-0.25)$ followed by HT and LO $(r=0.12)$; therefore, no strong linear relationship among the three traits was indicated. Test of fixed effects in statistical models indicated significant differences in LO, FR, and HT for the 34 clones across the four locations (Table 3 ).

Late spring frosts periodically damage crapemyrtles as plants break dormancy and begin growth. Plants that LO later in the spring should be less prone to the unsightly burn and growth delays associated with such damage. In 2005, LO began during the week of 14 Mar. in Mississippi, 21 Mar. in Florida and Alabama, and 11 Apr. in Tennessee. When location was treated as a fixed effect to evaluate difference at the four locations (Table 3 ), the location $\times$ clone interaction was nonsignificant indicating the sequence in which clones leafed out was very stable regardless of environment. BLUPs for all locations ranged from 1.73 for APA to 4.37 for WCS or $\approx 2.5$ weeks difference in LO (Table 4). Plants leafed out over 4 weeks in Florida, whereas the other locations required 5 weeks. Overall, location LO means for all clones indicate plants leafed out over a shorter duration in Florida and Tennessee than in Mississippi and Alabama. Cluster analysis of the means developed a three-cluster solution (Table 5). Seven of the L. indica clones were grouped into Cluster 1, the earliest LO group, whereas eight were in Cluster 2, the intermediate LO group. Eleven of the interspecific clones were in Cluster 1, whereas four were in Cluster 2. NAT, MUS and SAR, the only three interspecific hybrids resulting from a direct cross between $L$. indica and $L$. fauriei (Egolf, 1981a), clustered together in the intermediate group with the complex interspecific hybrid, OSA. The four $L$. fauriei clones (FAN, KIO, TOW, WCS) in the study clustered together into Cluster 3, the last group to LO. Apparently, L. fauriei germplasm has a greater tendency to maintain dormancy later in the spring than germplasm of $L$. indica.

Stability analysis showed the majority of the clones in this study to have $b_{1}$ values $\approx 1$, indicating relative stability (Table 6; Fig. 1A). However, departures from linearity $\left(\mathrm{s}_{\mathrm{d}}{ }^{2}\right)$ and low $r^{2}$ values indicated inconsistent stability or lack of definite stability for most clones. It appeared that the latter situation

Table 5. Spring leaf-out, flowering, and growth comparisons of 34 Lagerstroemia cultivars.

\begin{tabular}{|c|c|c|c|c|c|c|c|}
\hline Code & $\begin{array}{l}\text { Cluster for } \\
\text { leaf-out }^{z}\end{array}$ & $\begin{array}{l}\text { Flowering } \\
\text { period }^{\mathrm{y}}\end{array}$ & $\begin{array}{l}\text { Cluster for week of } \\
\text { first flower }\end{array}$ & Reported $\mathrm{ht}^{\mathrm{w}}$ & $\begin{array}{c}\text { Reported growth } \\
\text { class }^{\text {w }}\end{array}$ & $\begin{array}{l}\text { Reported growth } \\
\text { scale }^{\mathrm{w}}\end{array}$ & $\begin{array}{l}\text { Cluster for } \\
\text { plant } h t^{v}\end{array}$ \\
\hline$\overline{\mathrm{ACO}}$ & 1 & 2 & 3 & $1.5-3$ & Semidwarf & 1 & 1 \\
\hline APA & 1 & & 3 & $3-6$ & Intermediate & 2 & 2 \\
\hline ARA & 1 & & 2 & $>6$ & Tree & 3 & 1 \\
\hline $\mathrm{CAB}$ & 1 & 3 & 3 & $>6$ & Tree & 3 & 2 \\
\hline CAT & 1 & & 2 & $3-6$ & Intermediate & 2 & 1 \\
\hline CES & 1 & & 3 & $3-6$ & Intermediate & 2 & 1 \\
\hline $\mathrm{CHE}$ & 1 & & 2 & $3-6$ & Intermediate & 2 & 1 \\
\hline $\mathrm{CHO}$ & 1 & 3 & 2 & $>6$ & Tree & 3 & 3 \\
\hline CHR & 2 & & 2 & $1.5-3$ & Semidwarf & 1 & 1 \\
\hline $\mathrm{COU}$ & 2 & & 3 & $3-6$ & Intermediate & 2 & 3 \\
\hline FAN & 3 & 2 & 1 & $>6$ & Tree & 3 & 3 \\
\hline $\mathrm{KIO}$ & 3 & 2 & 1 & $>6$ & Tree & 3 & 3 \\
\hline MIA & 1 & 2 & 2 & $>6$ & Tree & 3 & 3 \\
\hline MUS & 2 & 1 & 1 & $>6$ & Tree & 3 & 3 \\
\hline NAT & 2 & 1 & 1 & $>6$ & Tree & 3 & 3 \\
\hline OSA & 2 & 2 & 2 & $3-6$ & Intermediate & 2 & 3 \\
\hline PEC & 1 & 1 & 2 & $1.5-3$ & Semidwarf & 1 & 1 \\
\hline POW & 1 & 3 & 2 & $3-6$ & Intermediate & 2 & 1 \\
\hline SAR & 2 & & 2 & $>6$ & Tree & 3 & 3 \\
\hline $\mathrm{SIO}$ & 1 & 3 & 3 & $3-6$ & Intermediate & 2 & 2 \\
\hline SPP & 2 & & 2 & Not published & Not published & & 1 \\
\hline TON & 1 & 3 & 2 & $1.5-3$ & Semidwarf & 1 & 2 \\
\hline TOW & 3 & 2 & 1 & $>6$ & Tree & 3 & 3 \\
\hline TUS & 1 & 2 & 3 & $>6$ & Tree & 3 & 3 \\
\hline TKE & 1 & 2 & 3 & $3-6$ & Intermediate & 2 & 3 \\
\hline TWI & 2 & & 3 & $>6$ & Tree & 3 & 2 \\
\hline VRD & 2 & 2 & 2 & $<1.5$ & Dwarf & -1 & 1 \\
\hline RAS & 2 & 3 & 3 & $3-6$ & Intermediate & 2 & 2 \\
\hline DYN & 1 & 3 & 3 & $3-6$ & Intermediate & 2 & 2 \\
\hline RER & 1 & 3 & 3 & $>6$ & Tree & 3 & 2 \\
\hline BUC & 2 & & 3 & $3-6$ & Intermediate & 2 & 1 \\
\hline SIR & 1 & & 3 & $1.5-3$ & Semidwarf & 1 & 1 \\
\hline WMT & 2 & 3 & 2 & $3-6$ & Intermediate & 2 & 2 \\
\hline WCS & 3 & & 2 & Not published & Not published & & 3 \\
\hline
\end{tabular}

${ }^{\mathrm{z}}$ Clusters of clones were determined using least squares means for week of leaf-out (across all locations) with hierarchical cluster analysis (Ward's method) with values for Cluster 1 ranging from 1.73 to 2.58, values for Cluster 2 ranging from 2.64 to 3.46, and values for Cluster 3 ranging from 3.78 to 4.37 .

${ }^{\mathrm{y}}$ Flowering season scale based on observations by Byers (2000) and Fare (1984) in which 1 = early and mid-June (early); $2=$ late June and early July (midseason); and 3 = mid- and late July (late).

${ }^{\mathrm{x}}$ Clusters of clones were determined using least squares means for week of first flower (across all locations) with hierarchical cluster analysis (Ward's method) with values for Cluster 1 ranging from 1.84 to 2.86, values for Cluster 2 ranging from 3.38 to 4.52 , and values for Cluster 3 ranging from 4.72 to 7.00 .

${ }^{w}$ Height and growth class and growth scale $[1=1.5-3 \mathrm{~m}$ (semidwarf); $2=3-6 \mathrm{~m}$ (intermediate); and $3=$ greater than $6 \mathrm{~m}$ (tree) $]$ reported by Franklin et al. (2006). ${ }^{v}$ Clusters of clones were determined using least squares means for plant height (across all locations) with hierarchical cluster analysis (Ward's method) with values for Cluster 1 ranging from 113.0 to $164.8 \mathrm{~cm}$, values for Cluster 2 ranging from 187.8 to $215.5 \mathrm{~cm}$, and values for Cluster 3 ranging from 229.0 to $301.1 \mathrm{~cm}$. 
Table 6. Stability characteristics ${ }^{z}$ for week of leaf-out, week of first flower, and plant height for 34 clones of Lagerstroemia grown at four locations in the southeastern United States.

\begin{tabular}{|c|c|c|c|c|c|c|c|c|c|}
\hline \multirow[b]{2}{*}{ Clone } & \multicolumn{3}{|c|}{ Week of leaf-out ${ }^{y}$} & \multicolumn{3}{|c|}{ Week of first flower } & \multicolumn{3}{|c|}{ Plant ht ${ }^{\mathrm{y}}$} \\
\hline & $\mathrm{b}_{1}{ }^{\mathrm{x}}$ & $\mathrm{s}_{\mathrm{b}}{ }^{\mathrm{w}}$ & $r^{2}$ & $\mathrm{~b}_{1}{ }^{\mathrm{x}}$ & $\mathrm{s}_{\mathrm{b}}{ }^{\mathrm{w}}$ & $r^{2}$ & $\mathrm{~b}_{1}{ }^{\mathrm{x}}$ & $\mathrm{s}_{\mathrm{b}}{ }^{\mathrm{w}}$ & $r^{2}$ \\
\hline$\overline{\mathrm{ACO}}$ & $1.91^{* *}$ & $0.26^{* *}$ & 0.71 & 1.35 & $0.37 * *$ & 0.37 & 1.49 & $0.31 * *$ & 0.51 \\
\hline APA & 1.43 & $0.31 * *$ & 0.48 & 1.46 & $0.44 * *$ & 0.34 & 1.26 & $0.24 * *$ & 0.55 \\
\hline ARA & 0.90 & $0.34^{*}$ & 0.24 & $1.63 *$ & $0.25 * *$ & 0.66 & 1.49 & $0.41 * *$ & 0.38 \\
\hline $\mathrm{CAB}$ & 0.75 & 0.43 & 0.12 & 0.81 & $0.24 * *$ & 0.35 & 0.80 & $0.22 * *$ & 0.37 \\
\hline CAT & 0.96 & $0.27 * *$ & 0.36 & 1.06 & $0.12 * *$ & 0.78 & 0.65 & $0.25 * *$ & 0.24 \\
\hline CES & $1.79 * *$ & $0.30 * *$ & 0.64 & 1.13 & $0.29 * *$ & 0.43 & 0.90 & $0.46^{*}$ & 0.16 \\
\hline $\mathrm{CHE}$ & 1.20 & $0.32 * *$ & 0.39 & 1.45 & $0.33^{* *}$ & 0.47 & 1.07 & $0.30 * *$ & 0.36 \\
\hline $\mathrm{CHO}$ & 1.51 & $0.39 * *$ & 0.41 & $2.35 * *$ & $0.29 * *$ & 0.74 & 0.50 & 0.32 & 0.10 \\
\hline CHR & $0.26^{* *}$ & 0.28 & 0.04 & $2.09^{*}$ & $0.47 * *$ & 0.49 & 0.50 & 0.29 & 0.12 \\
\hline $\mathrm{COU}$ & $0.34 * *$ & 0.20 & 0.12 & 0.80 & $0.38 *$ & 0.17 & 0.57 & $0.23 *$ & 0.23 \\
\hline FAN & 1.06 & $0.34 * *$ & 0.33 & 0.70 & 0.46 & 0.11 & $1.54 *$ & $0.41 * *$ & 0.41 \\
\hline $\mathrm{KIO}$ & $0.34 *$ & 0.26 & 0.09 & $0.37^{*}$ & 0.24 & 0.12 & 1.44 & $0.21 * *$ & 0.73 \\
\hline MIA & 1.34 & $0.21 * *$ & 0.64 & 0.92 & $0.28 * *$ & 0.33 & 0.78 & $0.19 * *$ & 0.43 \\
\hline MUS & $0.14 * *$ & 0.23 & 0.02 & $0.41 *$ & $0.34 *$ & 0.06 & $1.52 *$ & $0.19 * *$ & 0.75 \\
\hline NAT & 1.31 & $0.31 * *$ & 0.45 & $0.17 * *$ & 0.54 & 0.00 & 0.81 & $0.43^{*}$ & 0.14 \\
\hline OSA & 0.50 & 0.30 & 0.12 & 0.84 & $0.51^{*}$ & 0.11 & 0.67 & $0.19 * *$ & 0.35 \\
\hline PEC & $1.84^{* *}$ & $0.28 * *$ & 0.67 & $-0.19 * *$ & 0.58 & 0.00 & $2.08 *$ & $0.51 * *$ & 0.43 \\
\hline POW & 1.23 & $0.36 * *$ & 0.35 & 1.45 & $0.24 * *$ & 0.62 & 1.47 & $0.31 * *$ & 0.51 \\
\hline SAR & 0.54 & $0.22 * *$ & 0.21 & $2.51 * *$ & $0.38 * *$ & 0.67 & 0.69 & $0.23 * *$ & 0.29 \\
\hline $\mathrm{SIO}$ & $1.77 * *$ & $0.25 * *$ & 0.70 & $2.32 * *$ & $0.37 * *$ & 0.65 & 1.13 & $0.32 * *$ & 0.37 \\
\hline SPP & 0.87 & $0.22 * *$ & 0.42 & 1.53 & $0.31 * *$ & 0.53 & 0.94 & $0.43 *$ & 0.18 \\
\hline TON & 0.93 & $0.40^{*}$ & 0.20 & $-1.20 * *$ & $0.26 * *$ & 0.48 & 1.04 & $0.21 * *$ & 0.54 \\
\hline TOW & $0.15^{* *}$ & 0.20 & 0.02 & 1.54 & $0.36^{* *}$ & 0.45 & 0.70 & 0.41 & 0.12 \\
\hline TUS & $1.67 *$ & $0.22 * *$ & 0.72 & $1.60 *$ & $0.26 * *$ & 0.63 & 1.35 & $0.22 * *$ & 0.62 \\
\hline TKE & 0.82 & 0.47 & 0.12 & 0.61 & 0.50 & 0.06 & 1.13 & $0.29 * *$ & 0.41 \\
\hline TWI & 0.77 & $0.25 * *$ & 0.30 & 0.85 & $0.19 * *$ & 0.47 & $0.14 *$ & 0.30 & 0.01 \\
\hline VRD & $0.43^{*}$ & $0.20 *$ & 0.17 & 1.41 & $0.26 * *$ & 0.57 & $0.11 * *$ & 0.41 & 0.00 \\
\hline RAS & 1.08 & $0.28 * *$ & 0.41 & $0.11 * *$ & 0.30 & 0.01 & 1.32 & $0.25 * *$ & 0.56 \\
\hline DYN & 1.32 & $0.35 * *$ & 0.39 & $0.43 *$ & $0.24 * *$ & 0.12 & 1.27 & $0.25 * *$ & 0.53 \\
\hline RER & 0.76 & $0.25 * *$ & 0.30 & $0.19 * *$ & 0.22 & 0.03 & 1.02 & $0.24 * *$ & 0.44 \\
\hline BUC & 1.21 & $0.26^{* *}$ & 0.52 & 1.52 & $0.40 * *$ & 0.42 & 0.86 & $0.28 * *$ & 0.32 \\
\hline SIR & 1.23 & $0.31 * *$ & 0.42 & $0.40^{*}$ & 0.24 & 0.12 & 0.82 & $0.26 * *$ & 0.32 \\
\hline WMT & 1.00 & $0.42 *$ & 0.20 & $-1.37 * *$ & $0.41 * *$ & 0.34 & 0.73 & $0.27 * *$ & 0.25 \\
\hline WCS & $0.26^{* *}$ & $0.11 * *$ & 0.21 & $2.49 * *$ & $0.31 * *$ & 0.74 & $1.53 *$ & $0.22 * *$ & 0.69 \\
\hline
\end{tabular}

${ }^{\mathrm{z} S t a b i l i t y ~ c h a r a c t e r i s t i c s: ~} \mathrm{~b}_{1}$, coefficient of regression; $\mathrm{s}_{\mathrm{b}}$, SE of coefficient of regression; $r^{2}$, coefficient of determination.

${ }^{y}$ Calculated using the natural log of the response variable.

${ }^{\mathrm{x}} \mathrm{b}_{1}$ is statistically different from 1 at $\alpha=0.05(*)$ or $0.01(* *)$.

${ }^{w}$ Deviation from linearity $\left(\mathrm{s}_{\mathrm{d}}{ }^{2}\right)$ is statistically different from 0 at $\alpha=0.05(*)$ or $0.01(* *)$.

was attributable, in good part, to week of LO being measured on a discrete scale (as opposed to a continuous scale), making $\mathrm{s}_{\mathrm{d}}^{2}$ and $r^{2}$ less useful than $b_{1}$ for evaluating stability for this response variable. In addition, the limited number of environments (locations) used in this study may also make $s_{d}^{2}$ less useful for evaluating stability (Eberhart and Russell, 1966). Clones that tended to LO later, on average, than the other clones (including three of the L. fauriei clones: KIO, TOW, and WCS), exhibited values of $b_{1}$ closer to 0 , indicating greater insensitivity to environment. Clones with higher values of $\mathrm{b}_{1}$, indicating relatively greater sensitivity to environment among the clones included in this study, included mostly interspecific hybrids (ACO, PEC, SIO, and TUS) and only one clone of $L$. indica (CES).

Time of flowering is an important trait of many ornamental plants, including crapemyrtle. Earlier-flowering cultivars of summer flowering perennials are desired by retailers to stimulate sales before hot weather dampens customer enthusiasm. Landscape designers are interested in extending the flowering season by using a variety of clones that together extend the flowering season. Flowering in 2005 began the weeks of 2 May in Mississippi, 23 May in Florida, 13 June in Tennessee, and 20 June in Alabama. Flowering was probably delayed in Florida as compared with Mississippi by a more intensive cultural management program in Florida (trickle irrigation and higher levels of fertilization) that favored vegetative growth. BLUPs show two L. fauriei clones, KIO and FAN, had the earliest average flowering date across locations, whereas two L. indica clones, COU and RAS, were the latest to begin flowering (Table 7). When location was treated as a fixed effect to evaluate differences at the four locations (Table 3 ), the location $\times$ clone interaction was significant indicating the sequence in which clones flowered was sensitive to environment differences. There was an approximate 5-week difference between the earliest and latest clones to initiate flowering. Overall, location FR means for all clones at a location indicated that clones began flowering over a shorter duration in Florida and Mississippi than in Tennessee and Alabama (Table 7).

Cluster analysis of the FR means developed a three-cluster solution (Table 5). Three of the four $L$. fauriei clones (FAN, KIO, TOW) and two of the three initial interspe- cific crosses (NAT, MUS) comprised Cluster 1 with mean FRs ranging from 1.84 to 2.86 and were the earliest clones to begin flowering. Cluster 2 had intermediate mean FRs ranging from 3.38 to 4.52 and included one $L$. fauriei clone (WCS), eight interspecific clones (ARA, CHE, CHO, MIA, OSA, PEC, SAR, TON), and six L. indica clones (CAT, CHR, POW, SPP, VRD, WMT). Cluster 3, which included the last clones to initiate flowering, included nine $L$. indica clones (CAB, CES, COU, TWI, RAS, DYN, RER, BUC, SIR) and five interspecific clones (ACO, APA, SIO, TUS, TKE) with mean FRs ranging from 4.72 to 7.00 . Seventy-five percent of the $L$. fauriei clones were in the earlyflowering cluster, whereas $64 \%$ of the $L$. indica clones were in the late-flowered cluster. There is a discernible tendency for $L$. fauriei germplasm to flower earlier than germplasm of $L$. indica.

Comparison of the three clusters generated during analysis of this study using earlyseason (1), midseason (2), and late-season (3) designations for time of flowering with observations of 21 of the same clones in central Alabama (Fare, 1984) and north Alabama (Byers, 2000) indicated agreement on 10 clones (CAB, MIA, MUS, NAT, OSA, 

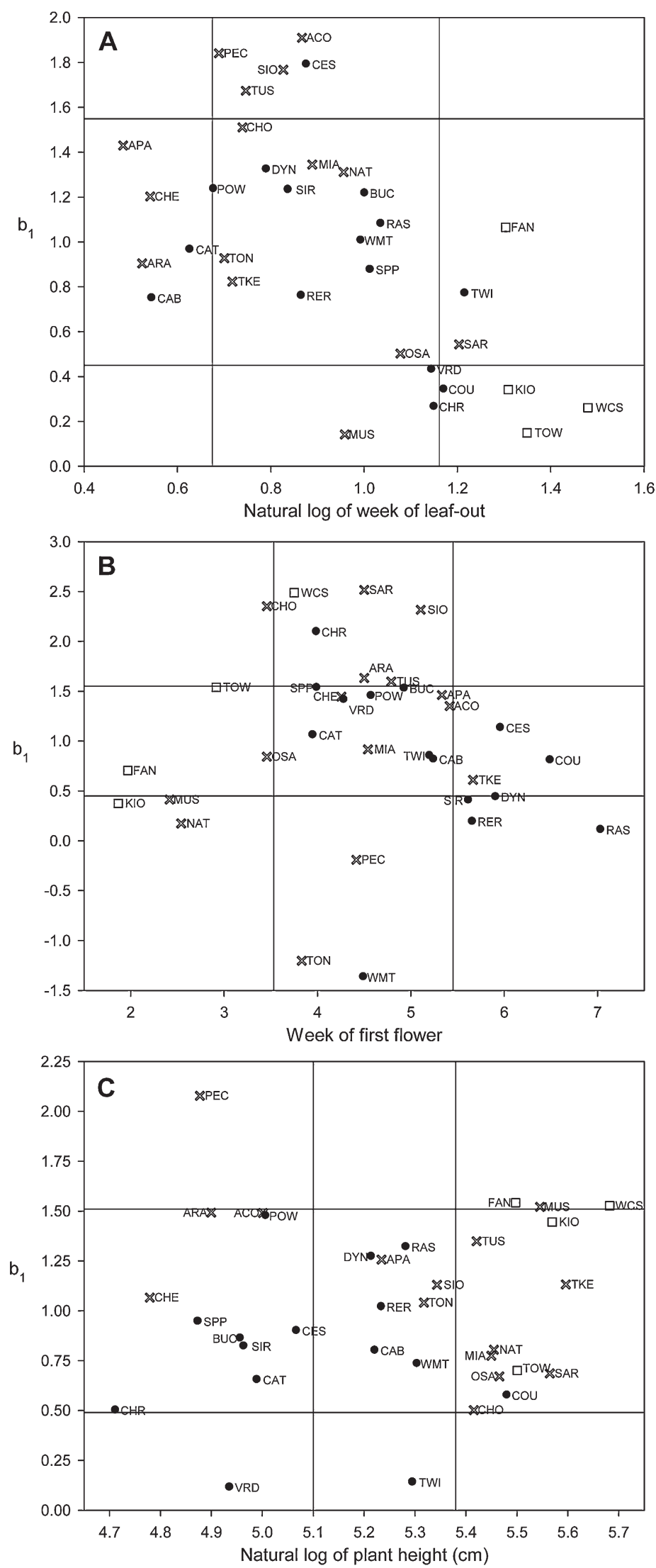

Fig. 1. Regression coefficients $\left(b_{1}\right)$ of least squares means over environmental index plotted against least squares means (across four locations in the southeastern United States) for 34 clones of Lagerstroemia for (A) natural log of the week of leaf-out, (B) week of first flower, and (C) natural log of plant height. Codes refer to names of clones (cultivars) indicated in Table 1 . Solid circles refer to $L$. indica clones, hollow circles refer to $L$. fauriei clones, and crosses refer to interspecific hybrids.
VRD, RAS, DYN, RER, SIO), whereas seven clones were indicated to flower earlier in this study (CHO, FAN, KIO, POW, TON, TOW, WMT) and four were indicated to flower later (ACO, PEC, TUS TKE) (Table 5), which approximated the differences observed at individual locations within this study (Table 7). Another 3-year study conducted in central Alabama (Creech et al., 1999) evaluated flowering of 17 tall clones, including 10 evaluated in this study (NAT, FAN, SAF, MIA, TUS, CHO, OSA, TKE, MUS, CAB) and observed that, on average, initiation of flowering occurred over 2 weeks centered on 1 July. Bolques and Knox (1997) reported flowering started from late May to mid-June for ACO, TON, APA, SIO, NAT, and MIA in north Florida.

Stability analysis indicated that approximately half of the clones in this study were moderately stable (values of $b_{1} \approx 1$ ) with respect to week of first flower (Table 6; Fig. 1B). Departures from linearity $\left(\mathrm{s}_{\mathrm{d}}{ }^{2}\right)$ were most often noted among clones having higher values of $b_{1}$; however, these same clones often tended to have higher $r^{2}$ values (greater than 0.50) compared with clones with lower values of $b_{1}$. However, as also noted previously regarding week of LO, week of first flower was measured on a discrete scale and a limited number of environments (locations) were used in this study, making $\mathrm{s}_{\mathrm{d}}^{2}$ and $r^{2}$ of questionable value in assessing stability of this trait. Two clones, TON and WMT, differed notably from the other clones by having $b_{1}$ values less than -1.0 , indicating a trend in sensitivity that was opposite to that of most other clones. The clones $\mathrm{CHO}, \mathrm{CHR}$, SIO, SAR, and WCS were the most sensitive to environment (values of $b_{1}$ greater than 2 ), whereas NAT, RER, and RAS were the most insensitive (values of $b_{1}$ closest to zero). Overall, it appeared that week of first flower was a less stable trait than week of LO or plant height.

Several researchers (Goi and Tanaka, 1976; Guidry, 1977; Stimart, 1986) have studied initiation of flowering in crapemyrtle in efforts to investigate its potential as a flowering pot plant. These studies found that temperature rather than photoperiod determined flowering but tests were unable to separate the interactions between light intensity and production temperature on flower initiation. Other self inductive crops such as azaleas (Criley, 1975) and roses (Moe and Kristoffersen, 1969) flower well in diverse climates with cool or warm summers, whereas crapemyrtle fails to flower in climates such as the United Kingdom and the Pacific Northwest with low heating degree days. In woody perennial genera such as Rubus, which have been studied extensively to determine the interactions between flowering and heat units, it was found that species and clones vary in their requirements and that factors such as plant vigor and cold damage can modify responses (Black et al., 2008).

Plant size is an important trait in crapemyrtle clones because it determines where plants can be properly situated in landscapes 
Table 7. Least squares means and best linear unbiased predictions (BLUPs) with 95\% confidence intervals for week of first flower of 34 clones of Lagerstroemia grown at four locations in the southeastern United States. ${ }^{\mathrm{z}}$

\begin{tabular}{|c|c|c|c|c|c|}
\hline$\overline{\text { Clone }}$ & All locations & Quincy, FL & McNeill, MS & Cullman, AL & McMinnville, TN \\
\hline$\overline{\mathrm{ACO}}$ & $5.35(4.10-6.98)$ & $4.44(3.42-5.76)$ & $4.73(3.66-6.11)$ & $6.07(4.77-7.73)$ & $6.43(5.07-8.16)$ \\
\hline APA & $5.26(4.03-6.87)$ & $4.62(3.57-5.99)$ & $4.47(3.44-5.79)$ & $5.52(4.31-7.07)$ & $6.73(5.31-8.51)$ \\
\hline ARA & $4.43(3.37-5.84)$ & $3.59(2.73-4.74)$ & $3.91(2.98-5.13)$ & $4.95(3.83-6.41)$ & $5.54(4.31-7.12)$ \\
\hline $\mathrm{CAB}$ & $5.20(3.98-6.79)$ & $4.34(3.34-5.64)$ & $4.80(3.71-6.20)$ & $5.66(4.42-7.24)$ & $6.20(4.87-7.89)$ \\
\hline CAT & $3.91(2.95-5.19)$ & $3.25(2.44-4.32)$ & $3.51(2.65-4.65)$ & $4.23(3.23-5.55)$ & $4.84(3.72-6.30)$ \\
\hline CES & $5.92(4.54-7.72)$ & $5.01(3.89-6.45)$ & $5.28(4.11-6.78)$ & $6.60(5.15-8.45)$ & $7.06(5.53-9.00)$ \\
\hline $\mathrm{CHE}$ & $4.20(3.17-5.56)$ & $3.41(2.57-4.52)$ & $3.75(2.84-4.95)$ & $4.67(3.59-6.09)$ & $5.20(3.98-6.80)$ \\
\hline $\mathrm{CHO}$ & $3.38(2.52-4.53)$ & $2.80(2.08-3.77)$ & $2.69(2.00-3.63)$ & $3.85(2.91-5.10)$ & $4.50(3.43-5.90)$ \\
\hline CHR & $3.93(2.95-5.23)$ & $3.11(2.33-4.15)$ & $3.42(2.58-4.55)$ & $4.44(3.40-5.82)$ & $5.03(3.83-6.61)$ \\
\hline $\mathrm{COU}$ & $6.44(4.98-8.33)$ & $5.80(4.55-7.38)$ & $5.70(4.47-7.27)$ & $6.57(5.20-8.31)$ & $7.93(6.35-9.90)$ \\
\hline FAN & $1.91(1.34-2.74)$ & $1.60(1.11-2.31)$ & $1.62(1.13-2.33)$ & $2.28(1.59-3.25)$ & $2.25(1.58-3.22)$ \\
\hline KIO & $1.84(1.26-2.68)$ & $1.60(1.08-2.37)$ & $1.57(1.07-2.29)$ & $2.06(1.43-2.97)$ & $2.20(1.51-3.22)$ \\
\hline MIA & $4.49(3.41-5.91)$ & $3.67(2.78-4.82)$ & $4.22(3.23-5.51)$ & $4.79(3.69-6.21)$ & $5.50(4.28-7.07)$ \\
\hline MUS & $2.39(1.73-3.30)$ & $2.08(1.50-2.89)$ & $2.00(1.43-2.78)$ & $2.85(2.08-3.90)$ & $2.74(2.00-3.76)$ \\
\hline NAT & $2.51(1.83-3.45)$ & $2.04(1.47-2.83)$ & $2.29(1.66-3.16)$ & $3.09(2.27-4.20)$ & $2.75(2.01-3.75)$ \\
\hline OSA & $3.41(2.54-4.57)$ & $3.02(2.25-4.05)$ & $2.74(2.03-3.69)$ & $4.13(3.13-5.45)$ & $3.95(2.98-5.22)$ \\
\hline PEC & $4.38(3.33-5.78)$ & $4.21(3.22-5.51)$ & $3.67(2.79-4.83)$ & $4.74(3.65-6.16)$ & $5.04(3.90-6.52)$ \\
\hline POW & $4.52(3.43-5.94)$ & $3.61(2.74-4.76)$ & $4.16(3.18-5.44)$ & $4.89(3.78-6.34)$ & $5.66(4.41-7.27)$ \\
\hline SAR & $4.40(3.34-5.80)$ & $3.47(2.63-4.59)$ & $3.72(2.82-4.89)$ & $5.11(3.95-6.60)$ & $5.70(4.44-7.32)$ \\
\hline SIO & $5.00(3.81-6.56)$ & $4.03(3.08-5.26)$ & $4.27(3.24-5.62)$ & $5.69(4.44-7.30)$ & $6.39(5.02-8.13)$ \\
\hline SPP & $3.94(2.97-5.23)$ & $3.27(2.46-4.34)$ & $3.37(2.54-4.47)$ & $4.45(3.41-5.82)$ & $4.91(3.78-6.38)$ \\
\hline TON & $3.82(2.87-5.08)$ & $3.38(2.54-4.49)$ & $3.72(2.81-4.91)$ & $4.23(3.23-5.56)$ & $4.01(3.04-5.27)$ \\
\hline TOW & $2.86(2.11-3.89)$ & $2.51(1.84-3.42)$ & $2.31(1.69-3.17)$ & $3.03(2.25-4.10)$ & $3.81(2.86-5.09)$ \\
\hline TUS & $4.72(3.60-6.20)$ & $3.85(2.94-5.05)$ & $4.26(3.27-5.56)$ & $5.01(3.88-6.47)$ & $6.04(4.73-7.72)$ \\
\hline TKE & $5.61(4.32-7.30)$ & $4.56(3.52-5.90)$ & $5.49(4.28-7.03)$ & $5.98(4.69-7.61)$ & $6.64(5.25-8.41)$ \\
\hline TWI & $5.16(3.95-6.74)$ & $4.39(3.38-5.71)$ & $4.68(3.62-6.06)$ & $5.49(4.28-7.03)$ & $6.27(4.93-7.97)$ \\
\hline VRD & $4.23(3.20-5.59)$ & $3.50(2.64-4.62)$ & $3.74(2.84-4.92)$ & $4.62(3.55-6.01)$ & $5.31(4.12-6.86)$ \\
\hline RAS & $7.00(5.43-9.03)$ & $6.10(4.80-7.73)$ & $6.67(5.29-8.42)$ & $7.35(5.86-9.21)$ & $8.05(6.46-10.04)$ \\
\hline DYN & $5.87(4.52-7.62)$ & $5.15(4.01-6.62)$ & $5.43(4.24-6.95)$ & $6.01(4.73-7.65)$ & $7.07(5.61-8.91)$ \\
\hline RER & $5.63(4.33-7.32)$ & $4.91(3.81-6.33)$ & $5.27(4.10-6.76)$ & $5.89(4.62-7.51)$ & $6.60(5.22-8.36)$ \\
\hline BUC & $4.86(3.69-6.40)$ & $3.97(3.00-5.26)$ & $4.36(3.34-5.69)$ & $5.32(4.08-6.92)$ & $6.07(4.75-7.75)$ \\
\hline SIR & $5.58(4.28-7.28)$ & $4.83(3.74-6.24)$ & $5.14(4.00-6.62)$ & $5.95(4.61-7.67)$ & $6.56(5.18-8.32)$ \\
\hline WMT & $4.48(3.41-5.90)$ & $4.02(3.07-5.26)$ & $4.33(3.32-5.65)$ & $5.08(3.93-6.57)$ & $4.57(3.52-5.94)$ \\
\hline WCS & $3.66(2.75-4.88)$ & $2.93(2.19-3.93)$ & $3.11(2.33-4.16)$ & $3.88(2.94-5.12)$ & $5.08(3.91-6.60)$ \\
\hline All clones & & $3.72 \mathrm{C}^{\mathrm{y}}$ & $3.93 \mathrm{C}$ & $4.86 \mathrm{~B}$ & $5.45 \mathrm{~A}$ \\
\hline
\end{tabular}

${ }^{\mathrm{z}}$ Least squares means were calculated for each clone across all locations and BLUPs were calculated for each clone at each location (with location as a random effect). Least squares means were calculated for each location across all clones (with location as a fixed effect in preliminary analysis).

${ }^{\mathrm{y}}$ Means at each location for all clones combined followed by the same letter are not significantly different according to the simulation-stepdown method at $\alpha=$ 0.05 .

and how fast producers can expect a particular clone to reach a marketable size. After 3 years in the field, BLUPs for clones in this study ranged from $113 \mathrm{~cm}$ for CHR to $301 \mathrm{~cm}$ for WCS (Table 8). Plants in Florida were greatest in height. The physical environmental at the Mississippi and Florida locations is very similar (Table 2), but plants in Florida were on a production regimen with supplemental irrigation and higher fertility, whereas plants in Mississippi were maintained on a postproducer regimen typical of landscape conditions. When location was treated as a fixed effect to evaluate differences at the four locations (Table 3 ), the location $\times$ clone interaction was significant indicating variation in how fast the clones grew in the various environments.

Cluster analysis of the HT means developed a three-cluster solution (Table 5). Cluster 1 means ranged from 113 to $164.8 \mathrm{~cm}$ and included four interspecific clones (ACO, CHE, ARA, PEC) and eight $L$. indica clones (CAT, CES, CHR, POW, SPP, VRD, BUC, SIR). Cluster 2 means ranged from 187.8 to $215.5 \mathrm{~cm}$, including three interspecific (APA, SIO, TON) and six L. indica clones (CAB, TWI, RAS, DYN, RER, WMT). Cluster 3 means ranged from 229 to $301.1 \mathrm{~cm}$ with all four L. fauriei clones (FAN, KIO, TOW,
WCS), one L. indica (COU), the initial interspecific hybrids (MUS, NAT, SAR), and the complex interspecific hybrids (CHO, OSA, TUS, TKE) in this cluster. Interspecific and $L$. fauriei clones selected for this study tended to be more vigorous than $L$. indica clones.

Johnson and Dix (1993) indicated that size classifications are indications of speed of growth rather than ultimate growth. Comparison of the three clusters generated during analysis of this study with the most recently published size groupings (Franklin et al., 2006) indicated agreement on 18 (ACO, APA, CHO, CHR, FAN, KIO, MIA, MUS, NAT, PEC, SAR, SIO, TOW, TUS, RAS, SIR, WMT, DYN) of 32 clones classified (Table 5). Our clusters indicated nine clones (ARA, CAB, CAT, CES, CHE, POW, TWI, RER, BUC) had a growth classification that was smaller than the published grouping, whereas our results grouped five clones (COU, OSA, TON, TKE, VRD) with larger growing clones. The difference in classification was most dramatic for ARA, which was reported to be a tree form (greater than $6 \mathrm{~m}$ ) but grew at a rate equivalent to the smaller growing clones grouped in Cluster 1 in this study. The clones SPP and WCS were found to produce growth equivalent to Clusters
1 and 3, respectively. This study is the first report on expected growth of these two clones.

Stability analysis indicated that most clones in this study were moderately stable (values of $b_{1} \approx 1$ ) with respect to plant height (Table 6; Fig. 1C). Most clones exhibited some departure from linearity $\left(\mathrm{s}_{\mathrm{d}}^{2}\right)$, indicating inconsistent stability; however, clones with $b_{1}$ values greater than 1.0 tended to have $r^{2}$ values greater than 0.50 , providing some stronger evidence for stability among these clones. Most L. fauriei and interspecific clones tended to have $b_{1}$ values greater than 1.0 , whereas most $L$. indica clones had $b_{1}$ values less than 1.0. The interspecific clone PEC exhibited a value of $b_{1}$ greater than 2.0, indicating that its growth rate in more favorable environments tends to exceed that of the other clones. The $L$. indica clones TWI and VRD had $b_{1}$ values less than 0.15 , indicting less sensitivity to environment than the other clones. Overall, most clones exhibited stability in plant height in different environments, but the stability was generally not consistent with the average response of all clones in these environments.

This study provides insight into the performance of selected crapemyrtle clones in the southeastern United States and identifies 
Table 8. Least squares means and best linear unbiased predictions (BLUPs) with $95 \%$ confidence intervals for plant height (cm) of 34 clones of Lagerstroemia grown for 3 years in field plots at four locations in the southeastern United States. ${ }^{2}$

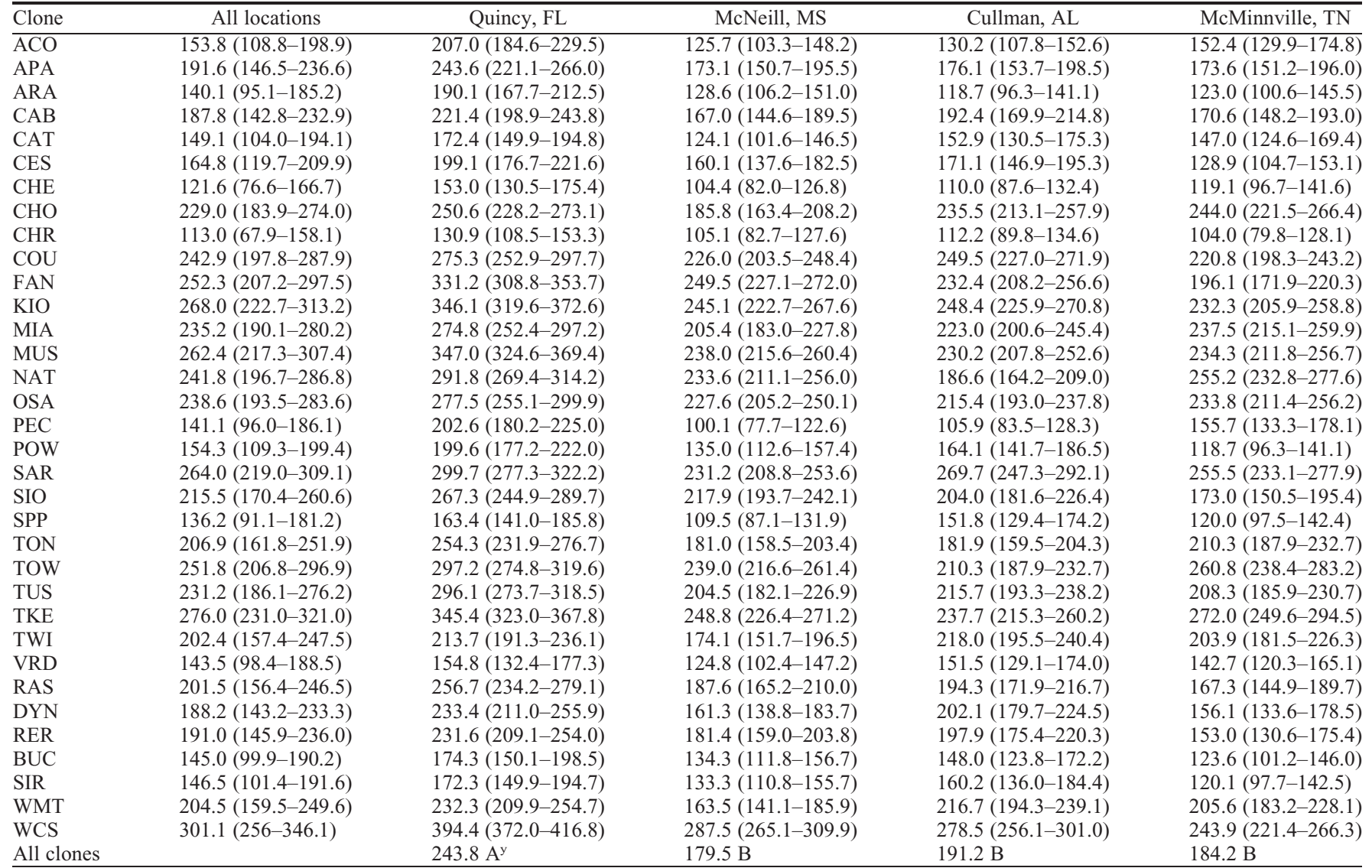

${ }^{\mathrm{z}}$ Least squares means were calculated for each clone across all locations and BLUPs were calculated for each clone at each location (with location as a random effect). Least squares means were calculated for each location across all clones (with location as a fixed effect in preliminary analysis).

${ }^{\mathrm{y}}$ Means at each location for all clones combined followed by the same letter are not significantly different according to the simulation-stepdown method at $\alpha=0.05$.

clones that should be promoted more in this geographic region as a result of LO and date of flowering. We found that changes in the growing environment affected time of flowering more than spring $\mathrm{LO}$ and growth rate in the majority of clones. First bloom was affected by environmental variation more with interspecific hybrids than with $L$. fauriei and $L$. indica clones. Evaluation in multiple environments refined the classification of the expected LO, first flower, and landscape size for tested clones. Clones of L. fauriei and clones originating from the initial cross between $L$. indica and $L$. fauriei were generally later to LO, earlier to flower, and more vigorous growers than $L$. indica or the complex $L$. indica $\times L$. fauriei clones.

Because this study was conducted in multiple environments and subjected to more rigorous statistical standards, consideration should be given to updating projected growth for clones, which this study indicates are misclassified. Information generated by this study will allow crapemyrtle breeders, landscape professionals, and consumers to better select the most appropriate crapemyrtle clone for a particular application.

\section{Literature Cited}

AHS Heat Zone Map. 2009. Developed by American Horticulture Society to show the average number of days each year that a given region experiences 'heat days,' temperatures over $30^{\circ} \mathrm{C}$ $\left(86^{\circ}\right.$ F). 22 Sept. 2009. <http://www.ahs.org/ publications/heat_zone_map.htm>.

Becker, H.C. and J. Leon. 1988. Stability analysis in plant breeding. Plant Breed. 101:1-23.

Black, B., J. Frisby, K. Lewers, F. Takeda, and C. Finn. 2008. Heat unit model for predicting bloom dates in Rubus. HortScience 43:20002004.

Blythe, E.K. and D.J. Merhaut. 2007. Grouping and comparison of container substrates based on physical properties using exploratory multivariate statistical methods. HortScience 42:353363.

Bolques, A. and G.W. Knox. 1997. Growth and flowering phenology of six crapemyrtle cultivars in north Florida. SNA Research Conf. Proc. 42:365-368.

Byers, M.D. 1997. Crapemyrtle: A grower's thoughts. Owl Bay Publishers, Inc., Auburn, AL.

Byers, M.D. 2000. Crapemyrtle comparisons chart. Byers Nursery Company, Inc., Huntsville, AL.

Cabrera, R.I., J.A. Reinert, and C. McKenney. 2008. Differential resistance among crape myrtle (Lagerstroemia) species, hybrids, and cultivars to foliar feeding by adult flea beetle (Altica litigate). HortScience 43:403-407.

Cabrera, R.I. 2003. Nitrogen balances for two container-grown woody ornamental plants. Scientia Hort. 97:297-308.

Cabrera, R.I. and D.R. Devereaux. 1999. Crape myrtle post-transplant growth as affected by nitrogen nutrition during nursery production. J. Amer. Soc. Hort. Sci. 124:94-98.
Cabrera, R.I. and D.R. Devereaux. 1998. Effects of nitrogen supply on growth and plant nutrient status of containerized crape myrtle. J. Environ. Hort. 16:98-104.

Creech, G., C. Gilliam, G. Keever, A. Hagan, J. Graveman, R. Brantley, and D. Williams. 1999. Crapemyrtle cultivar performance in Alabama. SNA Research Conf. Proc. 44: 470-472.

Criley, R.L. 1975. Effects of light and temperature on flower initiation and development, p. 52-61. In: Kofranek, A.M. and R.A. Larson (eds.). Growing azaleas commercially. Univ. of Calif., Sale Publication 4058.

Davis, E. and D. Fare. 1995. Cold hardiness evaluation of eight crapemyrtle cultivars. SNA Research Conf. Proc. 40:328-330.

Devereaux, D.R. 1996. Nitrogen nutrition of two woody ornamentals (holly and crape myrtle) and its effect on landscape establishment. MS thesis, Rutgers University, New Brunswick, NJ.

Dix, R.L. 1999. Cultivars and names of Lagerstroemia. U.S. National Arboretum. Posted to U.S. National Arboretum web site 6 Jan. 2005. 22 Sept. 2009. <http://www.usna.usda.gov/ Research/Herbarium/Lagerstroemia/index.html $>$.

Eberhart, S.S. and W.A. Russell. 1966. Stability parameters for comparison of varieties. Crop Sci. 6:36-40.

Egolf, D.R. 1967. Four new Lagerstroemia indica L. cultivars-'Catawba', 'Conestoga', 'Potomac' and 'Powhatan'. Baileya 15:7-13.

Egolf, D.R. 1981a. 'Muskogee' and 'Natchez' Lagerstroemia. HortScience 16:576-577. 
Egolf, D.R. 1981b. 'Tuscarora' Lagerstroemia. HortScience 16:788-789.

Egolf, D.R. 1986a. 'Tuskegee' Lagerstroemia. HortScience 21:1078-1080.

Egolf, D.R. 1986b. 'Acoma', 'Hopi', 'Pecos', and 'Zuni' Lagerstroemia. HortScience 21:12501252.

Egolf, D.R. 1987a. 'Biloxi', 'Miami', and 'Wichita' Lagerstroemia. HortScience 22:336-338.

Egolf, D.R. 1987b. 'Apalachee', 'Comanche', 'Lipan', 'Osage', 'Sioux', and 'Yuma' Lagerstroemia. HortScience 22:674-677.

Egolf, D.R. 1990. 'Caddo' and 'Tonto' Lagerstroemia. HortScience 25:585-587.

Egolf, D.R. and A.O. Andrick. 1978. The Lagerstroemia Handbook/Checklist. American Association of Botanical Gardens and Arboreta, Inc.

Fare, D. 1984. An evaluation of shade and ornamental trees for the southeast. MS thesis, Auburn Univ., Auburn, AL.

Finlay, K.W. and G.N. Wilkinson. 1963. The analysis of adaptation in a plant breeding programme. Aust. J. Agr. Res. 14:742-754.

Franklin, B., S. Owens, and N. Sperry. 2006. Crape myrtle comparisons chart. The Crape Myrtle Trails of McKinney Foundation, McKinney, TX.

Gill, D. and A. Owens. 2007. Crape myrtles for Louisiana landscapes. Pub. 1466. La. Coop. Ext. Ser., Baton Rouge, LA.

Goi, M. and Y. Tanaka. 1976. Effect of photoperiod and temperature on growth and flowering in Lagerstroemia indica L. Tech. Bull. Fac. Agr. Kagawa Univ. (Japan) 27:77-83.

Guidry, R.K. 1977. Forcing Dwarf Crapemyrtles. MS thesis, Univ. of Ark., Fayetteville, AR.

Hagan, A.K., G.J. Keever, C.H. Gilliam, J.D. Williams, and G. Creech. 1998. Susceptibility of crapemyrtle cultivars to powdery mildew and Cercospora leaf spot in Alabama. J. Environ. Hort. 16:143-147.

Hayes, C.L. and O.M. Lindstrom. 1992. Cooling and warming effects on cold hardiness estimations of three woody ornamental taxa. HortScience 27:1308-1309.

Hill, J. 1975. Genotype-environmental interactions: A challenge for plant breeding. J. Agr. Sci. (Cambridge) 85:477-493.

Holcomb, G.E. 1994. Susceptibility rating of crape myrtle cultivars to Cercospora leaf spot. LAES Mimo Series 95:30-31.
Johnson, R. and R. Dix. 1993. Dwarf crape myrtle classification. SNA Res. Conf. Proc. 38:374 378.

Knox, G.W. 1996. Evaluation of crape myrtle cultivars in north Florida. SNA Research Conf. Proc. 41:270-272.

Knox, G.W. 2008. Crape myrtle in Florida. Publication ENH-52. Coop. Ext. Ser., Univ. of Fla. Gainesville, FL.

Knox, G.W., R.F. Mizell, III, and D.O. Chellemi. 1993. Susceptibility of crape myrtle cultivars to crape myrtle aphid and powdery mildew. SNA Research Conf. Proc. 37:340-342.

Knox, G.W. and J.G. Norcini. 1991. Lagerstroemia cultivars under evaluation at the NFRECMonticello. Proc. Fla. State Hort. Soc. 104: 346-347.

Laiche, A.J. and J.M. Anderson. 1996. Crape myrtle cultivar evaluation. Miss. Agr. For. Expt. Sta. Res. Rpt. 21:1-4.

Lindstrom, O.M., R.B. Beverly, and H.A. Mills 2002. Neither bloom period nor postbloom nitrogen application reduces cold hardiness in crapemyrtle. Commun. Soil Plant. Anal. 33: 3837-3844.

Littell, R.C., G.A. Milliken, W.W. Stroup, R.D Wolfinger, and O. Schabenberger. 2006. SAS for mixed models. 2nd Ed. SAS Institute Inc., Cary, NC.

Martin, C.A. and J.M. Ruter. 1996. Growth and foliar nutrient concentration of crape myrtle in response to disparate climate and fertilizer placement in large nursery containers. J. Environ. Hort. 14:9-12.

Mizell, R.F., III and G.W. Knox. 1993. Susceptibility of crape myrtle, Lagerstroemia indica L., to the crapemyrtle aphid, Tinocallis kahawaluokalani (Kirkaldy) in north Florida. J. Entomol. Sci. 28:1-7.

Moe, R. and T. Kristoffersen. 1969. The effect of temperature and light on growth and flowering of Rosa 'Baccara' in greenhouses. Acta Hort. 14:157-166.

NOAA Satellite and Information Service, National Environmental Satellite, Data, and NOAA Information Service (NESDIS). 2009. Satellite and information. 22 Sept. 2009. <http://www7. ncdc.noaa.gov/IPS/cd/cd.html>

Ortiz, R. and J. Izquierdo. 1994. Yield stability differences among tomato genotypes grown in Latin America and the Caribbean. HortScience 29:1175-1177.
Pair, J.C. and L. Parsons. 1996. Crape myrtle evaluations. Agr. Expt. Sta. Rpt. of Progress 770:4-5

Pettis, G.V., D. Boyd, S. Braman, and C. Pounders 2004. Potential resistance of crape myrtle cultivars to flea beetle (Coleoptera: Chrysomelidae) and Japanese beetle (Coleoptera: Scarabaeidae) damage. J. Econ. Entomol. 97:981-992.

Pooler, M.R. 2006. 'Arapaho' and 'Cheyenne' Lagerstroemia. HortScience 41:855-856.

Pooler, M.R. and R.L. Dix. 1999. 'Chickasaw', 'Kiowa', and 'Pocomoke' Lagerstroemia. HortScience 34:361-363.

Pounders, C., S. Reed, and M. Pooler. 2006. Comparison of self- and cross-pollination on pollen tube growth, seed development, and germination in crapemyrtle. HortScience 41: 575-578.

Robinson, G.K. 1991. That BLUP is a good thing: The estimation of random effects. Stat. Sci. 6:15-32.

Stimart, D.P. 1986. Lagerstroemia, p. 187-190. In: Halevy, A.H. (ed.). Handbook of flowering. Vol. 5. CRC Press, Inc, Boca Raton, FL.

USDA Hardiness Zone Map. 2009. Developed to detail the lowest temperatures that can be expected each year in the United States, Canada, and Mexico. 22 Sept. 2009. <http://www.usna. usda.gov/Hardzone/index.html $>$.

USDA Soil Classification. 2009. 22 Sept. 2009. $<$ http://soils.usda.gov/technical/classification/>.

Wade, G.L. and J. Williams-Woodward. 2001. Crape myrtle culture. Leaflet 331. Ga. Coop. Ext. Serv. Athens, GA.

Whitcomb, C.E. 1985. 'Centennial Spirit' crapemyrtle. HortScience 20:1144-1145.

Whitcomb, C.E. 1999. Five new crapemyrtles. Lacebark Inc., Stillwater, OK.

Whitcomb, C.E. 2000a. Crape myrtle shrub named 'Whit II'. In: The U.S. Patent and Trademark Office. PP10296.

Whitcomb, C.E. 2000b. Crape myrtle plant named 'Whit IV'. In: The U.S. Patent and Trademark Office. PP11342.

Whitcomb, C.E. 2004. Crape myrtle plant named 'Whit VII'. In: The United States Patent and Trademark Office. PP14975.

Whitcomb, C.E., C. Gray, and B. Cavanaugh. 1984. 'Prairie Lace' crapemyrtle. HortScience 19:737-738.

Williams, D., K. Tilt, and S. Valenti-Windsor. 2000. Common crapemyrtle. Publication ANR-1083. Ala. Coop. Ext. Serv. Auburn, AL. 